\title{
Research of Evolution Mechanism of Network Group Event Based on Grounded Theory under Micro-Blog Platform
}

\author{
Haiying Ma \\ Department of Management Science and Engineering, East China University of Science \& Technology, Shanghai, \\ China \\ Email: c mhy@163.com
}

Received 16 September 2015; accepted 12 October 2015; published 15 October 2015

Copyright (C 2015 by author and Scientific Research Publishing Inc.

This work is licensed under the Creative Commons Attribution International License (CC BY). http://creativecommons.org/licenses/by/4.0/

c) (i) Open Access

\begin{abstract}
At this stage, China society in conflict-prone period, the network group events developed rapidly. Network group events had a significant impact on society. The trend which the online group event evolved into the offline group incidents is becoming evident. In this paper, we used grounded theory to study the evolution and the development process of network group events under the micro-blog platform. We present an evolution mechanism model of network group event under micro-blog platform and find the formation mechanism of the network of public opinion, intrinsic motivation and the evolution of the network group events.
\end{abstract}

\section{Keywords}

Network Group Events, Micro-Blog, Grounded Theory

\section{Introduction}

As the number of Internet users continues to rise, the network group event has developed rapidly, and online and offline mass incidents linked trends are becoming evident [1]. In the dissemination of information, micro-blog almost integrates all the advantages of previous network communication tools [2]. In China, micro-blog has become the most active, the most influential and the most variable forms of media, and therefore it showed tremendous energy on the public opinion gathered [3]. Not only in the domestic, in the spring of 2011 the "Arab Spring” movement, early the riots in London and other British cities and the "Occupy Wall Street” campaign in the fall of the United States, have shown that the micro-blog has a strong ability of Mobilization cross social class and cross region. Network media initiated network community events and become the real driving force of 
social group events [4]. In summary, the in-depth study of group events of network has become a top priority of the current researchers, and has a very important significance for maintaining social stability and unity and building a harmonious society. At present, the research on the cause and the mechanism of the evolution of the group events, most people find the relevant theories from abroad sociology, psychology to explain the domestic group events (such as Guan Kai (2009); Wu Xueting (2009); Yu Jianrong (2009)). This kind of borrowing foreign theory to analyze the practice of the domestic group events has ignored the special features of the Chinese people, and it is impossible to realize the social psychology of the Chinese people. Feng Yan (2009) of China and the United States, "human flesh search" conducted a comparative study, the researchers showed that Chinese and foreign mass incidents there is a big difference. So it is necessary for us to use the new research method to study the causes and mechanisms of Chinese online group events.

\section{Method and Data}

\subsection{Research Methods}

American sociologist Anselm Strauss and Glaser Barney proposed grounded theory in 1967. It is an exploratory and inductive theory of discovery from complex phenomena. It can help researchers discover the theory from qualitative data, rather than verify theory that already exists [5]. Grounded theory is very much emphasis on the collection and analysis of raw data and information, adhere to the idea of all the data, rooted in the data, and on the basis of these data and information to summarize the theory. The method has advantages over other methods in the aspect of hypothesis establishment and theory development. Using this method helps to make some original discoveries. Since the study attempts to dig out the intrinsic motivation of network group events and psychological perception process from the chaos of the individual behavior of Internet users. The study is essentially exploratory study. Therefore, this article choose grounded theory as the primary method.

\subsection{Data Sources}

The data of this paper mainly come from sina micro-blog. Sina micro-blog is a kind of Twitter website, which is launched by Sina. Sina micro-blog is a well-known micro-blog platform, the news report is rich and reliable. And there are hot micro-blog ranking, you can collect every day of the hot micro-blog. Taking into account the timeliness of the micro-blog, we put the search time limit from January 1, 2014 to March 31, 2014. We select a micro blog every day, a total of 90 micro-blog text. In addition, in order to further understand and analyze the relevant content of the micro-blog text, we also selected more than 100 cases related to micro-blog. Some of the information is about the whole process of micro blog, some of the background and reasons, some of which are obtained from the perception, etc.

\section{Data Analysis and Results}

For collect the data, we use the grounded theory to carry on the three level decoding.

\subsection{Three Coding}

The first step is to open the decoder. We use the concept to express the data, and classified concept of similar properties to form category. The purpose of opening the decoder is to identify the phenomenon, define the concept and found the category, which is handling the amassed issue. In order to tap the micro-blog factors caused network mass incidents, we opened coding the 90 micro text and 154 case text, sentence by sentence and paragraph by paragraph to analysis, ensure the code to fit the data. After several finishing Analysis, we got the following categories. Table 1 is the category through open coding the micro-blog text. Table 2 is the category through open coding the case material. By opening decoding, we downsized the information, abstracted and refined case to some extent.

Next, we find and establish the connection between the categories through the spindle encoding. Every time the category is analyzed, the relevant relationship is sought. So that we will be able to join the separate categories, re-integrate the decomposed data, and then select the most relevant areas of the research questions to form the main category.

In the analysis of the micro blog text, we divide all kinds of authentication into the category of "certification". 
Table 1. The category of open coding the micro-blog text.

\begin{tabular}{cclc}
\hline Category & $\begin{array}{c}\text { The number of } \\
\text { micro-blog text }\end{array}$ & \multicolumn{1}{c}{ Category } & $\begin{array}{c}\text { The number of } \\
\text { micro-blog text }\end{array}$ \\
\hline Celebrity certification & 20 & Video Evidence & 4 \\
Site Certification & 2 & Photographic evidence & 57 \\
Media Certification & 35 & News and other textual evidence & 12 \\
Enterprise Certification & 1 & Web Links & 18 \\
Authentication & 14 & Scientific evidence & 5 \\
Micro-Bardon & 13 & Time qualifiers excite a sense of urgency & 2 \\
Government Certification & 5 & Description of powerful groups inspire emotion & 4 \\
Detailed description Time & 7 & Description of disadvantaged arouse emotion & 10 \\
Location Detailed Description & 6 & Description of the facts that have occurred excite emotion & 25 \\
Detailed data description & 9 & Assertion increase credibility & 2 \\
condition description & 46 & Suggest & 23 \\
Quick description & 24 & Description of many people doing inspire herd mentality & 1 \\
Description parties & 4 & The tone of questioning and condemnation excited emotion & 8 \\
no evidence & 17 & Simple statement & 26 \\
\hline
\end{tabular}

Table 2. The category of open coding the case text.

\begin{tabular}{|c|c|c|}
\hline Number & Category & Concept \\
\hline 1 & $\begin{array}{l}\text { Public cognitive and emotional for } \\
\text { micro-blog indicated parties }\end{array}$ & $\begin{array}{l}\text { Public awareness of the poor, the disabled and other vulnerable groups; public awareness } \\
\text { of the government, the wealthy and other powerful groups }\end{array}$ \\
\hline 2 & $\begin{array}{l}\text { Public cognitive and emotional for } \\
\text { micro-blog indicated objects }\end{array}$ & Public awareness of food safety, environmental pollution, traffic conditions, etc. \\
\hline 3 & $\begin{array}{l}\text { Public awareness of the extent of } \\
\text { laws and regulations }\end{array}$ & Public awareness of food safety, demolition and other laws and regulations, etc. \\
\hline 4 & $\begin{array}{l}\text { Public understanding of the extent of } \\
\text { scientific knowledge }\end{array}$ & Public understanding of natural phenomena, knowledge of life, chemistry knowledge \\
\hline 5 & $\begin{array}{l}\text { Timeliness of government and } \\
\text { related institutions to publish events }\end{array}$ & $\begin{array}{l}\text { Whether the Government and relevant institutions published the specific circumstances } \\
\text { related events in time, rather than delayed or withheld }\end{array}$ \\
\hline 6 & $\begin{array}{l}\text { Timeliness of government and } \\
\text { relevant institutions to respond to events }\end{array}$ & Timely response to media and other related events broke, not indifferent \\
\hline 7 & $\begin{array}{l}\text { Public reaction to the government's } \\
\text { attitude on this event }\end{array}$ & The public towards the government's attitude of the incident is still in favor of or not \\
\hline 8 & $\begin{array}{l}\text { Public reaction to the media about } \\
\text { the incident attitude }\end{array}$ & $\begin{array}{l}\text { The public towards the media attitude about the incident is still believe or not, is the } \\
\text { approval or opposition }\end{array}$ \\
\hline 9 & $\begin{array}{l}\text { Public reactions to celebrity, micro- } \\
\text { Bardon, roots and other attitude } \\
\text { about the event }\end{array}$ & $\begin{array}{l}\text { The public for celebrities, micro Bo's people, the grassroots attitude of the incident is still } \\
\text { believe or do not believe, is to agree or disagree }\end{array}$ \\
\hline 10 & $\begin{array}{l}\text { Public about the experience or } \\
\text { understanding of the event }\end{array}$ & $\begin{array}{l}\text { Experience of the public for the event, the public's knowledge of the event, such as fire, } \\
\text { earthquake, etc. }\end{array}$ \\
\hline 11 & $\begin{array}{l}\text { believe and follow micro-blog } \\
\text { network group behavior }\end{array}$ & The public believe that the micro blog content and follow the network group behavior. \\
\hline 12 & $\begin{array}{l}\text { Do not believe and follow micro-blog } \\
\text { network group behavior }\end{array}$ & $\begin{array}{l}\text { The public do not believe in micro blog co } \\
\text { ntent but follow the network group behavior, such as a lot of Internet users do not believe } \\
\text { the disadvantages of the mask, but in order to be safe they involved in the process }\end{array}$ \\
\hline 13 & $\begin{array}{l}\text { do not know, but follow the network } \\
\text { micro-blog group behavior }\end{array}$ & $\begin{array}{l}\text { The public do not know the contents of the micro blog but also choose to follow the } \\
\text { network group behavior, such as a lot of Internet users do not know the situation of the } \\
\text { starfish epidemic, but they feel meaningful and active forwarding }\end{array}$ \\
\hline 14 & $\begin{array}{l}\text { Other group behavior impacts on } \\
\text { their own }\end{array}$ & $\begin{array}{l}\text { Such as the incident of buying, a lot of people do not believe that micro-blog and other } \\
\text { network rumors, but they are afraid to affect their daily lives and join them. }\end{array}$ \\
\hline 15 & Associated with evidence & $\begin{array}{l}\text { Such as Starbucks acknowledged the ingredients in coffee, so many people began to find } \\
\text { the relevant scientific evidence, and compared with foreign countries, to stimulate the } \\
\text { emotional of people }\end{array}$ \\
\hline 16 & Propagation velocity of micro-blog & $\begin{array}{l}\text { Micro-blog has timeliness, if the micro-blog quickly spread, will stimulate the interest of } \\
\text { everyone involved in it. }\end{array}$ \\
\hline 17 & Network Group Events & $\begin{array}{l}\text { We actively participate in the forwarding, comments, analysis, etc., and even extended to } \\
\text { our real life, gradually formed a network group events. }\end{array}$ \\
\hline
\end{tabular}


The different descriptions are classified into the category of "description method", and all kinds of evidence is the category of "list of evidence". Finally, we divide all kinds of emotion into the category of "emotional factor". In this way, the four main categories of "certification", "description method", "list of evidence", "emotional factor" are formed, see Table 3.

Finally, we carry out selective decoding. We have carried out a systematic analysis of all the categories, and choose the core category. It can concentrate related category in a wide range of theories to realize the analysis and focus of the category. In simple terms, it is to find the main events of networking groups to prepare for the establishment of model.

Table 4, the number of category 7, 8, 9, 10, 11 is "the main body involved in the collection behavior of classification." Table 4, the number of Category 1 and 2 are the public factors; category number 3 and 4 are the government status as a source of information. Table 4, the number of Category 5 and 6 are situational factors. Table 3, the four categories are micro-blog text features.

\subsection{The Formation Mechanism of Network Group Events in the Micro-Blog Platform}

Through the analysis of the data, we found that after the spread of micro-blog, the public participated in the event of the network can be divided into three categories: those who believe micro-blog; those who do not believe the micro-blog; those who do not understand the micro-blog. In order to build a complete and comprehensive model, we analyze the influence factors of the three kinds of subjects' participation behavior.

\subsubsection{The Influence Factors of the People Who Believe the Micro-Blog Participating in the Network Group Events}

Before micro-blog had not been confirmed or overthrown, the public see it as information. So, the most critical

Table 3. The main category of micro blog text.

\begin{tabular}{|c|c|c|}
\hline Main category & Category & Number of micro-blog text \\
\hline \multirow{7}{*}{ Certification } & Media Certification & 35 \\
\hline & Celebrity certification & 20 \\
\hline & Authentication & 14 \\
\hline & Micro-Bardon & 13 \\
\hline & Government Certification & 5 \\
\hline & Site Certification & 2 \\
\hline & Enterprise Certification & 1 \\
\hline \multirow{6}{*}{ Description method } & Description of things & 46 \\
\hline & Quick description & 24 \\
\hline & Detailed data description & 9 \\
\hline & Detailed description Time & 7 \\
\hline & Location Detailed Description & 5 \\
\hline & Description parties & 4 \\
\hline \multirow{6}{*}{ List of evidence } & Photographic evidence & 57 \\
\hline & Web Links & 18 \\
\hline & No evidence & 17 \\
\hline & News and other textual evidence & 12 \\
\hline & Scientific evidence & 5 \\
\hline & Video Evidence & 4 \\
\hline \multirow{9}{*}{ Emotional factor } & Simple statement & 26 \\
\hline & Statement of facts that have occurred arouse public emotions & 25 \\
\hline & Suggest & 23 \\
\hline & Statement of vulnerable groups in order to stimulate public emotion & 10 \\
\hline & Taking questioning way arouse public emotions & 8 \\
\hline & Statement of strong group in order to stimulate public emotion & 4 \\
\hline & Increase the credibility of assertions & 2 \\
\hline & Time qualifier to increase the sense of urgency & 2 \\
\hline & State a lot of people to take the action to arouse the herd mentality & 1 \\
\hline
\end{tabular}


Table 4. The main category of case.

\begin{tabular}{|c|c|c|}
\hline Serial number & Main category & Category \\
\hline 1 & Public Memory and Cognition & $\begin{array}{l}\text { Public cognitive and emotional for micro-blog indicated parties; Public } \\
\text { cognitive and emotional for micro-blog indicated objects; Public about } \\
\text { the experience or understanding of the event }\end{array}$ \\
\hline 2 & Public knowledge of the reserves & $\begin{array}{l}\text { Public awareness of the extent of laws and regulations; Public } \\
\text { understanding of the extent of scientific knowledge }\end{array}$ \\
\hline 3 & $\begin{array}{l}\text { Timeliness of the government as a source of } \\
\text { information }\end{array}$ & $\begin{array}{l}\text { Timeliness of government and related institutions to publish events; } \\
\text { Timeliness of government and relevant institutions to respond to events }\end{array}$ \\
\hline 4 & $\begin{array}{l}\text { Government credibility as an information } \\
\text { source }\end{array}$ & $\begin{array}{l}\text { Timeliness of government and relevant institutions to respond to events; } \\
\text { Public reaction to the media about the incident attitude; Public reactions } \\
\text { to celebrity, micro-Bardon, roots and other attitude about the event }\end{array}$ \\
\hline 5 & Propagation velocity of micro-blog & Propagation velocity micro-blog \\
\hline 6 & Associated with evidence & Associated with evidence \\
\hline 7 & $\begin{array}{l}\text { Those who do not understand the } \\
\text { micro-blog }\end{array}$ & Some participants who do not understand the micro-Blog \\
\hline 8 & Those who believe micro-blog & Some participants who believed micro-blog \\
\hline 9 & Those who do not believe micro-blog & Some participants who do not believed micro-blog \\
\hline 10 & Herd (who does not believe micro-blog) & Herd who does not believe micro-blog \\
\hline 11 & Herd (who do not know micro-blog) & Herd who do not know micro-blog \\
\hline 12 & Network Group Events & Network Group Events \\
\hline
\end{tabular}

factor leading to the network group event is whether the micro-blog information can affect the attitude of the public acceptance micro-blog. Through research, the "micro blog text feature", "social public factor", "government as information source", "situational factors" are the four factors that influence public trust.

The first is the text features of micro-blog, it refers to the micro-blog own characteristics whether has credibility, such as micro-blog certification status, the evidence, the method of describing, the emotional factors. The social public factor mainly includes the public memory and the cognition and the public knowledge reserve, etc. In brief, it is the public's cognition and emotion to the people, events, things, which are formed in the daily life and social experiences. These are the important basis of public judgment and cognition. If the micro-blog content with the public perception and emotion, then the public tend to believe the micro-blog. Regarding the status of the government as a source of information, on the one hand, the government announced the incident is timely; on the other hand, the government responded to the incident in time. After the Internet exposed the events that have a greater impact on the government or the everyday life, the public tends to look forward to the government's official news. If the government does not respond in time, the public will think that this is the default performance or something to hide. In both cases, the expansion of the development trend of events. These two situations will expand the development trend of events. The last is the situational factor, which is the speed of the spread of micro blog and the relevant evidence. We can understand it as a condition of the public participation in the network group event. The speed of communication, and the evidence associated with it, will increase the credibility of the event. Under the influence of these four factors, the public may be more actively involved and it will form network group events.

\subsubsection{Factors Involved in Networking Groups Events for Those Who Do Not Believe or Do Not Know Micro-Blog}

In the process of case material analysis, we found that there are some who do not believe in and do not know micro-blog were also involved in the group event. Further analysis of this part of the people. It can be divided into the following three conditions:

1) Those who do not believe the micro-blog predict the affect of behavior of others, and participate in the network group events. Such as the incident of buying, a lot of people do not believe that micro-blog and other network rumors, but they are afraid to affect their daily lives and join them.

2) Those who do not believe the micro-blog follow the behavior of others to take actions. Such as Flight events of Malaysia, with the progress of the situation, the various versions of it have emerged, including even 
the time of black holes. Although many people do not believe this kind of micro-Blog, but taking into account everyone to pray for the loss of flight personnel, so they took forwarding, comments and other acts.

3) Those who do not understand the micro-Blog to take action. This can also use the case of buying to illustrate, many people do not know why everyone is buying, but most people's mind is that since we are doing, I do not have any harm to do it, so to join the inexplicable.

\subsubsection{Network Group Events Evolve Mechanisms Model}

According to the above analysis results, we construct a model of network group event evolution mechanism, as shown in Figure 1. For this model to make the following explanation, natural start is the micro-blog produces, is nothing more than three cases: believe micro-blog, do not believe that micro-blog (dubious or skeptical also belong to those people) and don't know micro-blog.

First, for those who believe micro-blog, according to the above analysis there are four factors that will make them more inclined to believe micro-blog. 1) micro-blog text features. For example, media certification, celebrities certification, micro-Bardon certification micro-blog often have more convincing; 2) social public factor. For example, the vulnerable groups are more likely to resonate; 3 ) as a condition of government information sources. If the government in this incident, publish, respond in a timely and effective, then we tend to believe the government. If the government response delay, even take deliberately delayed and hide the information. The public is more prefer to believe the media or celebrities micro-blog, even if just a guess; 4) situational factors. For example, the speed of a specific event spread faster, and the more relevant evidence, the public have more reason to believe the truth of this micro-blog. The readers believe the micro-blog, and to take appropriate measures under the micro-blog stimulus, gradually form network group events.

The second, for those who do not believe micro-blog, these people do not believe that the so-called crisis micro-blog exposed. But the actions taken by others may influence their actions. So they participate in it.

Finally, for those who do not understand the micro-blog content. For them, it was just a daily to buy food in supermarket, to see a large group of people in the rush to buy, although do not understand why, or to grab the first, that is the so-called herd mentality.

Overall, the public who believe that the micro-blog take action to form a network group events. Their behavior also affects those who do not believe or do not know micro-blog and gradually form the larger network group events.

\section{Conclusion}

From the above data and models, we can draw the following important information: 1) the government should further improve the timeliness and reliability of micro blog release, response; 2) adding time, place and other details can increase the credibility of the micro blog; 3 ) in the micro-blog editor, add photos, Web links and other evidence can increase the credibility of this micro blog; 4) the addition of mood words is conducive to stimulate

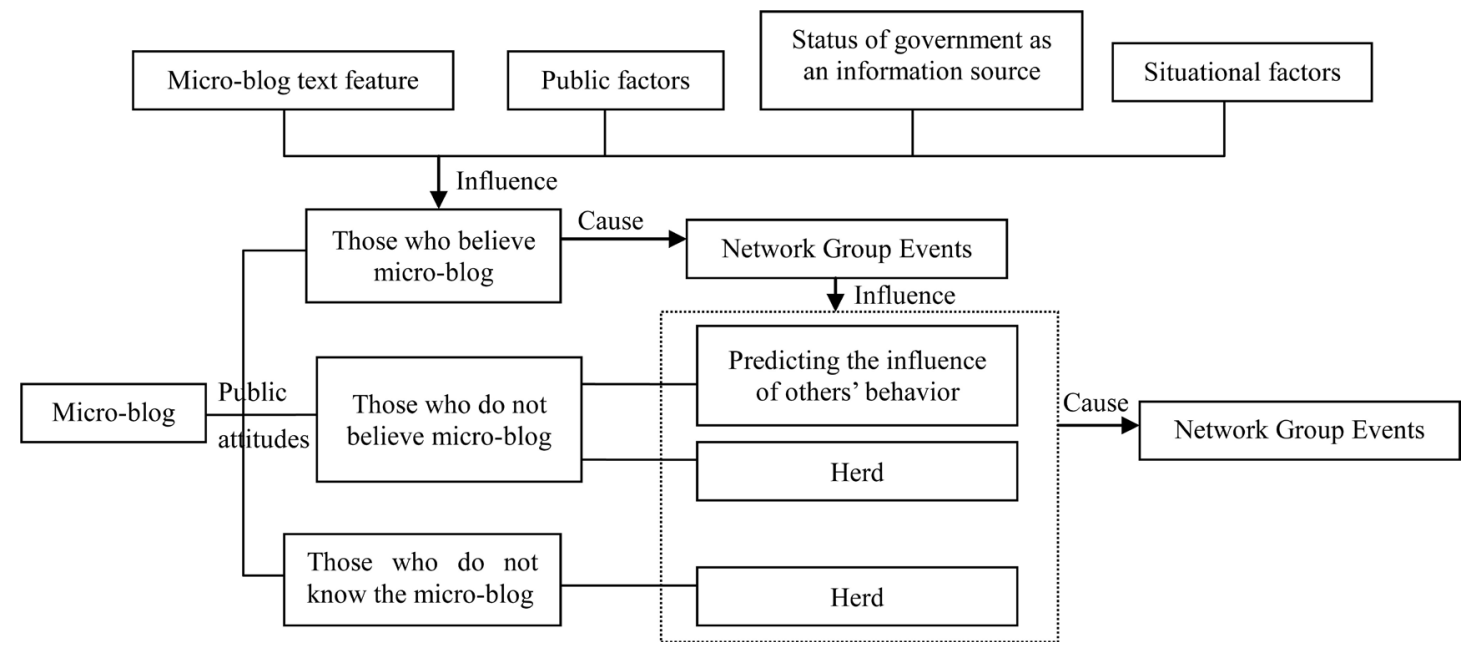

Figure 1. Network group event evolution mechanism base micro-blog platform. 
public sentiment; 5) many of the causes of the network group event is due to the lack of common sense of people and the value of the defect; 6) the media, micro-blog celebrity and other influence is relatively large, which requires the government to take effective supervision and guidance measures, on the other hand, the government should establish a good cooperative relationship with them, and gradually form a group to guide social mainstream; 7) micro-blog will trigger a chain reaction.

\section{Acknowledgements}

Research on the social science of the Ministry of Education, the research on the evolution mechanism of network group events and emergency strategy research under the micro blog platform, 13YJCZH124.

\section{References}

[1] Chinese Academy of Social, Blue Book-2010, China Social Situation Analysis and Prediction.

[2] Guo, H.X. (2012) The New Social Network Information Dissemination Characteristics and Model Analysis. Modern Intelligence, 1, 56-59.

[3] Chen, Y.H. (2010) See Micro-Blog Propagation Mechanism from the Incident. Media Observation, 8, 45-46.

[4] Li, L.K. (2013) Micro-Blog-Era of Mass Emergency Management of Public Opinion Response. People’s Forum, 23.

[5] Strauss, A. and Corbin, J. (1994) Grounded Theory Methodology-An Overview. In: Norman, K.D. and Vannaeds, S.L.Y., Eds., Handbook of Qualitative Research, Sage Publications, Thousand Oaks, 22-23. 